\title{
Kajian Paparan Panas Lingkungan Kerja Operator Sterilizer Pabrik Pengolahan Kelapa Sawit
}

\author{
Willy Tambunan ${ }^{* 1}$, Muslimin ${ }^{2}$ \\ ${ }^{1}$ Program Studi Teknik Industri, Fakultas Teknik, Universitas Mulawarman \\ ${ }^{2}$ Program Studi Teknik Elektro, Fakultas Teknik, Universitas Mulawarman \\ Jalan Sambaliung No. 9 Kampus Gunung Kelua Samarinda, 75119 \\ Email: ${ }^{* 1}$ willytambunan@ft.unmul.ac.id, ${ }^{2}$ muslimin@ft.unmul.ac.id
}

\begin{abstract}
Abstrak
Temperatur yang tinggi dalam ruangan kerja bisa ditimbulkan oleh kondisi ruangan, mesin-mesin ataupun alat yang mengeluarkan panas serta panas yang bersumber dari sinar matahari yang memanasi atap ruangan yang kemudian menimbulkan radiasi ke dalam ruangan produksi. Lingkungan kerja yang panas ini terjadi pada salah satu proses pengolahan kelapa sawit yakni sterilizer. Pada bagian sterilizer timbul panas akibat perebusan tandan buah segar dengan memakai media panas yakni uap yang berasal dari steam dan panas yang dihasilkan dari radiasi sinar matahari melalui atap pabrik menambah beban panas ruangan kerja. Akibat proses pengantaran panas tersebut suhu ruangan di area sterilizer dapat mencapai antara $34,3{ }^{\circ} \mathrm{C}$ s/d $36,6{ }^{\circ} \mathrm{C}$ sehingga pekerja mengalami cidera dan terjadi heat stress. Apabila kondisi ini terus berlangsung maka akan mengakibatkan resiko pada pekerja akibat heat stress. Untuk itu perlu dilakukan kajian paparan panas pada area sterilizer agar pekerja berada pada kondisi yang aman dan sehat dalam melakukan pekerjaannya di area tersebut. Berdasarkan hasil kajian diperoleh nilai Heat Stress Index (HSI) sebesar 98\% yang artinya bahwa operator yang bekerja pada bagian sterilizer berisiko tinggi terhadap penyakit yang diakibatkan heat stress. Melalui kajian paparan panas ini diharapkan lingkungan kerja yang terpapar panas berada pada nilai indeks suhu bola basah pada kondisi yang aman sesuai Keputusan Menteri Tenaga Kerja No.51/KEP-MEN/1999.
\end{abstract}

Kata kunci: heat stress, indeks suhu bola basah, keseimbangan panas, paparan panas

\section{PENDAHULUAN}

Lingkungan kerja adalah segala sesuatu yang ada di sekitar pekerja dan yang dapat mempengaruhi dirinya dalam menjalankan tugas-tugas yang dibebankan, misalnya lingkungan fisik, fisiologis, kimia, biologis, dan sosial ekonomi. Lingkungan kerja yang tidak nyaman seperti temperatur yang melebihi nilai ambang batas (NAB) dan sirkulasi udara yang tidak nyaman. Temperatur yang melebihi NAB mengakibatkan panas yang dapat mempengaruhi performansi kerja dan juga kesehatan tubuh pekerja. Hasil penelitian Huda \& Pandiangan (2012) menyebutkan bahwa temperatur ruang kerja yang terlampau panas akan mengakibatkan cepat timbulnya kelelahan tubuh dan dalam bekerja cenderung membuat banyak kesalahan sehingga bisa menurunkan prestasi kerja. Temperatur dalam ruangan kerja sangat mempengaruhi produktivitas dan kesehatan kerja (Stanton, et. al, 2004). Temperatur yang tinggi dalam ruangan kerja bisa ditimbulkan oleh kondisi ruangan, mesin-mesin ataupun alat yang mengeluarkan panas serta panas yang bersumber dari sinar matahari yang memanasi atap pabrik yang kemudian menimbulkan radiasi kedalam ruangan kerja produksi. 
Kondisi paparan panas tempat kerja merupakan suatu kondisi lingkungan kerja yang dipengaruhi oleh beberapa aspek lingkungan kerja fisik. Adapun aspek-aspek tersebut dapat berupa temperatur, kelembaban relatif, pergerakan udara serta aspek personal seperti insulasi pakaian dan jenis kegiatan. Kondisi panas dapat mengakibatkan kenyamanan dan juga ketidaknyamanan dalam bekerja. Ketidaknyamanan kerja dapat disebabkan oleh adanya paparan panas di tempat kerja. Paparan panas terjadi ketika tubuh menyerap atau memproduksi panas yang lebih besar dari pada yang diterima melalui proses regulasi panas. Paparan panas akibat adanya temperatur yang tinggi dalam ruangan kerja bisa ditimbulkan oleh kondisi ruangan, mesin-mesin ataupun alat yang mengeluarkan panas serta panas yang bersumber dari sinar matahari yang memanasi atap pabrik yang kemudian menimbulkan radiasi kedalam ruangan kerja sterilizer.

Lingkungan kerja yang panas ini terjadi pada pabrik pengolahan kelapa sawit, dimana temperatur pada ruangan sterilizer antara $34,3^{\circ} \mathrm{C}$ s/d $36,6^{\circ} \mathrm{C}$ yang dalam proses produksinya terdapat panas yang timbul akibat proses perebusan tandan buah segar dan panas yang dihasilkan dari radiasi sinar matahari melalui atap pabrik menambah beban panas ruangan kerja. Pekerja di bagian sterilizer merebus Tandan Buah Segar (TBS) dengan memakai media pemanas. Media tersebut adalah uap basah yang berasal dari sisa pembuangan turbin uap yang bertekanan $\pm 3 \mathrm{~kg} / \mathrm{cm} 2$ dan temperatur $\pm 145{ }^{\circ} \mathrm{C}$. Dalam sterilizer dilapisi Wearing Plat setebal $10 \mathrm{~mm}$ yang berfungsi untuk menahan uap yang berasal dari boiler. Di bawah sterilizer terdapat lubang yang gunanya untuk pembuangan air kondesat agar pemanasan di dalam sterilizer tetap seimbang. Proses perebusan ini biasanya berlangsung selama 90 menit dengan menggunakan uap air yang berkekuatan antara 280 sampai $290 \mathrm{Kg}$ /ton TBS. Proses ini dapat menghasilkan kondensat (cairan) yang mengandung sekitar $0,5 \%$ minyak. Kondensat ini kemudian dimasukkan ke dalam Fat Pit, yang nantinya dapat digunakan dalam membantu proses press daging sawit.

Akibat proses penghantaran panas yang terjadi pada proses sterilizer ini, terjadi ketidakseimbangan panas di lingkungan kerja produksi. Hal ini terlihat dari terganggunya sistem thermo regulatory tubuh pekerja, yang pada umumnya pekerja di bagian sterilizer ini menghasilkan keringat dengan jumlah yang banyak, sehingga efek panas langsung ke kulit. Adapun panas yang langsung ke kulit dapat menyebabkan terjadinya stroke pada pekerja. Karena terganggunya sistem thermoregulatory pekerja ini juga terlihat pada pekerja yang mengalami kehilangan panas (heat loss) tubuh pekerja akibat lingkungan panas yang besar. Oleh karena itu, suatu regulasi pengaturan distribusi panas yang baik di bagian sterilizer sangat diperlukan untuk diteliti agar persentase dan frekuensi operator mengambil waktu untuk minum maupun beristirahat dapat ditentukan dengan lebih baik sehingga produktivitas kerja diharapkan dapat meningkat.

Berdasarkan hasil pengamatan operator yang bekerja pada bagian sterilizer bekerja mulai pukul 07.00 WITA s/d 19.00 WITA. Hal ini menyebabkan indeks keringat yang dihasilkan pekerja semakin tinggi. Untuk mendapatkan keseimbangan panas operator biasanya mengambil waktu sejenak di area sekitar sterilizer yang tidak terpapar panas. Hal ini menyebabkan produktivitas operator semakin menurun. Berdasarkan kondisi ini maka penting dilakukan suatu kajian agar operator yang bekerja pada bagian sterilizer pengolahan kelapa sawit dapat 
Tekinfo -- Jurnal IImiah Teknik Industri dan Informasi -- 33

bekerja dengan nyaman dan kondisi tubuh dapat menyeimbangkan dengan kondisi lingkungan kerja.

\section{METODE PENELITIAN}

Obyek penelitian yang diamati adalah operator yang bekerja pada bagian sterilizer pada pabrik pengolahan kelapa sawit. Data yang diambil selama penelitian adalah data kondisi termal ruangan produksi dan data kondisi termal operator. Dua kondisi termal tersebut telah sesuai dengan penelitian yang dilakukan Huda \& Pandiangan (2012) yang mengatakan bahwa kenyamanan termal dapat diprediksi dengan mengkombinasikan faktor termal lingkungan dengan persepsi psikologi termal operator. Penentuan subyek dalam penelitian ini dilakukan seperti yang terdapat dalam teori sampling secara non-probability sampling, yaitu judgement sampling. Penarikan sampel menggunakan metode ini dengan pertimbangan dimana populasi dianggap bersifat homogen (Walpole, 1995).

Pengumpulan data dilakukan dengan menggunakan beberapa alat ukur yaitu Thermo-Hygrometer yang berfungsi untuk mengukur kelembapan relatif udara dan suhu ruangan, Black Glove Thermometer yang berfungsi untuk mengukur suhu bola kering, suhu bola basah dan suhu bola, Anemometer yang berfungsi mengukur kecepatan udara, Automatic Blood Pressure yang berfungsi untuk mengukur tekanan darah dan denyut nadi, dan termometer tubuh yang berfungsi untuk mengukur suhu tubuh. Data psikologi termal operator menggunakan Personal Questionnairre yang terdiri dari sensasi termal, kondisi aliran udara yang terjadi dan yang diharapkan, kenyaman termal yang terjadi dan efek dari lingkungan kerja, dan identifikasi kelelahan fisik. Keseluruhan faktor psikologi tersebut diteliti pada saat sebelum dan sesudah operator bekerja, sedangkan kondisi termal lingkungan diteliti pada saat operator sedang bekerja.

Pada penelitian ini akan memperhitungkan Heat Stress Index (HSI) dan Wet Bulb Globe Temperature (WBGT) atau sering pula disebut sebagai Indeks Suhu Bola Basah (ISBB). Metode HSI digunakan untuk melihat besarnya indeks tekanan paparan panas yang dirasakan operator dalam ruangan. Metode ISBB digunakan untuk menentukan proporsi waktu kerja dan waktu istirahat ketika bekerja pada ruangan yang terpapar panas (Stanton, et. al, 2004). Sedangkan metode untuk mengurangi termal lingkungan kerja operator dilakukan dengan mengurangi penyerapan panas dan perpindahan panas dengan pengendalian panas secara konduksi dan konveksi (Salvendy, 2012). Kerangka konseptual berfikir dalam penelitian ini sebagai berikut:

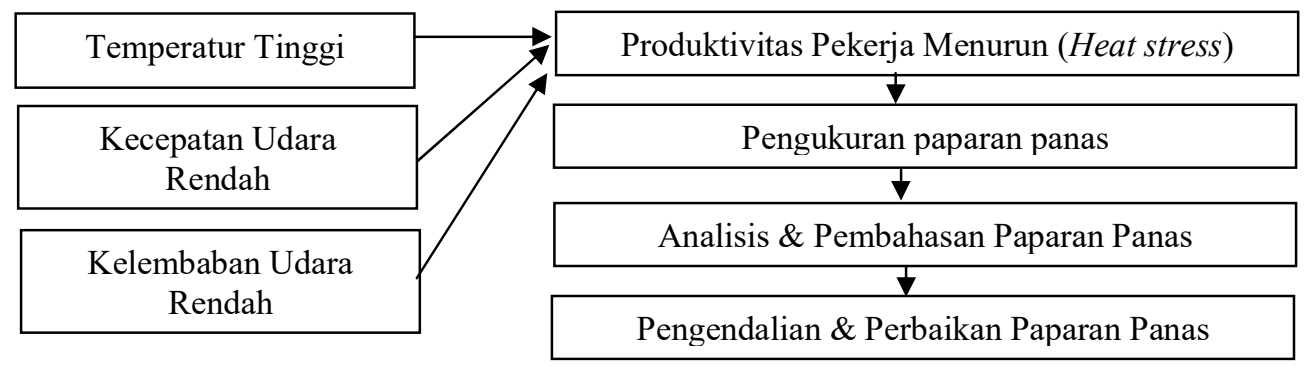

Gambar 1. Kerangka Konseptual

Vol. 7 - No. 1; November 2018 
Metode yang diambil untuk mengolah data adalah metode grafik yang dilakukan dengan membandingkan gambar-gambar grafik kondisi temperatur ruangan $(\mathrm{T})$, kecepatan udara $(\mathrm{V})$, kelembaban $(\mathrm{RH})$, grafik pengaruh ketinggian terhadap suhu dan kecepatan udara, grafik area permukaan tubuh Dubois, grafik data psikologi operator (kuesioner penilaian sensasi termal oleh pekerja), grafik indeks suhu bola basah, perbandingan denyut nadi, suhu tubuh dan tekanan darah pada waktu sebelum dan sesudah bekerja. Metode statistik meliputi uji kecukupan data, uji regresi dan korelasi pengaruh ketinggian terhadap suhu, pengaruh kecepatan angin terhadap suhu dan pengaruh kelembaban terhadap suhu, perhitungan nilai rata-rata, standar deviasi, area permukaan tubuh Dubois data personal, perhitungan mean vote, perhitungan indeks suhu bola basah (ISBB) dan perhitungan keseimbangan panas.

Sedangkan analisis dilakukan dengan menggunakan metode non statistik, adapun metode non statistik yang digunakan dalam analisis yaitu: Analisis grafik hasil penelitian temperatur ruangan (T), kecepatan udara (V), kelembaban $(\mathrm{RH})$ dan kuesioner termal yang ada di pabrik dan membandingkannya dengan standar kenyamanan yang diterapkan oleh ASHRAE (ASHRAE, 1985) yaitu, analisis grafik hasil penelitian dengan standar kenyamanan termal yang dikeluarkan Menteri Tenaga Kerja tentang nilai ambang batas (NAB) faktor fisika di tempat kerja. Metode statistik, adapun metode statistik yang digunakan dalam analisis yaitu: Analisis regresi dan korelasi untuk melihat hubungan antara variabel bebas (faktor lingkungan: suhu, kecepatan udara, kelembaban relatif, suhu basah, suhu kering dan suhu bola serta faktor manusia yakni tingkat metabolisme dan insulasi pakaian) juga hubungan tekanan darah, denyut nadi dan suhu tubuh terhadap kesehatan pekerja.

\section{HASIL DAN PEMBAHASAN}

Hasil pengolahan data pada komponen-komponen keseimbangan termal dapat dilihat pada Tabel 1.

Tabel 1. Komponen-Komponen Keseimbangan Termal

\begin{tabular}{ll}
\multicolumn{1}{c}{ Komponen } & \multicolumn{1}{c}{ Parameter } \\
\hline Suhu rata-rata $\left({ }^{\mathrm{O}} \mathrm{C}\right)$ & 35,79 \\
Rata-rata pencahayaan ruangan $(\mathrm{Lux})$ & 23,59 \\
Rata-Rata kecepatan Angin $(\mathrm{m} / \mathrm{s})$ & 0,08 \\
Kebutuhan energi sebelum bekerja (Kkal/menit) & 1,287 \\
Kebutuhan energi sesudah bekerja (Kkal/menit) & 1,598 \\
Pengaruh ketinggian terhadap suhu ruangan & $\mathrm{Y}=35,79+1,776$ (sangat kuat) \\
Pengaruh kelembapan terhadap suhu ruangan & $\mathrm{Y}=61,09-0,1762$ (sangat kuat) \\
Pengaruh kecepatan angin terhadap suhu & $\mathrm{Y}=0,150+0,011$ (sangat lemah) \\
Indeks suhu basah dan bola ISBB $\left({ }^{\mathrm{O}} \mathrm{C}\right)$ & 34,27 \\
Rat-rata Iclo & $0,5 \mathrm{Clo}$ \\
Kelembaban $(\%)$ & 61,09 \\
\hline
\end{tabular}


Keseimbangan termal adalah antara panas yang dihasilkan dengan panas yang dikeluarkan oleh ASHRAE (ASHRAE, 1985) memberikan persamaan keseimbangan panas sebagaimana persamaan (1).

$$
\mathrm{M}-\mathrm{W}=(\mathrm{C}+\mathrm{R}+\mathrm{Esk})+(\text { Cres }+ \text { Eres })
$$

(1)

dimana:

M : tingkat produksi energi metabolism

W : tingkat pekerjaan mekanik

Qsk : total tingkat kehilangan panas dari kulit

Qres : tingkat kehilangan panas dari pernapasan

C : tingkat kehilangan panas konvektif dari kulit

$\mathrm{R} \quad$ : tingkat kehilangan panas radiatif dari kulit

Esk : tingkat kehilangan panas penguapan total dari kulit

Cres : tingkat kehilangan panas konvektif dari pernapasan

Eres : tingkat kehilangan panas penguapan dari pernapasan

Untuk menyelesaikan persamaan keseimbangan termal, digunakan parameter sebagai berikut:

$\begin{array}{lll}\text { Re,cl } & =0,015 \mathrm{~m}^{2} \mathrm{kPa} \mathrm{W}^{-1} \\ \text { Tsk } & =36,15^{\mathrm{O}} \mathrm{C} \\ \text { Metabolisme rate } & =150 \mathrm{~W} \mathrm{~m}^{-2} \\ \text { Eksternal work } & =0 \mathrm{~W} \mathrm{~m}^{-2} \\ \text { Pakaian } & =0,70 \mathrm{Clo} \\ \text { Rcl } & =0,1085 \text { atau }(0,70 \mathrm{Clo} \times 0,155) \mathrm{m}^{2} \mathrm{C} \mathrm{W}^{-1} \\ \text { E } & =0,95 \\ \text { Ar/AD } & =0,77 \\ \text { AD } & =1,65 \mathrm{~m}^{2} \\ \text { Catatan } & & =1 \mathrm{Clo}^{\circ}=0,155 \mathrm{~m}^{2} \mathrm{C} \mathrm{W}^{-1} \\ \text { Tcl } & & =38{ }^{\circ} \mathrm{C}\end{array}$

Dengan demikian, penyelesaian persamaan keseimbangan termal dapat diuraikan sebagai berikut:

Metabolisme produksi panas $\mathrm{W} \mathrm{m}^{-2}=\mathrm{M}-\mathrm{W}=150-0=150$

$$
\begin{aligned}
\mathrm{Fcl} & =1+0,31 \mathrm{Clo}=1+(0,31 \mathrm{Rcl}: 0,155) \\
& =1+0,31(0,1085) / 0,155 \\
& =1,217
\end{aligned}
$$

untuk tsk $36,15{ }^{\mathrm{O}} \mathrm{C}$ maka diperoleh tekanan Psk,s $=\operatorname{Exp} 18,956-\frac{4030,18}{t s k+235}$

$$
\begin{aligned}
& \text { Psk,s }=\operatorname{Exp} 18,956-\frac{4030,18}{36,15+235} \\
& \text { Psk,s }=2,23 \mathrm{kPa}
\end{aligned}
$$

Untuk ta $=35,79{ }^{\circ} \mathrm{C}$ maka tekanan suhu udara

$$
\begin{aligned}
& \text { Psa }=\text { Exp 18,956- } \frac{4030,18}{t s k+235} \\
& \text { Psa }=\operatorname{Exp} 18,956-\frac{4030,18}{35,79+235} \\
& \text { Psa }=2,19 \mathrm{kPa}
\end{aligned}
$$

$\mathrm{Pa}=\mathrm{RH} \times \mathrm{Psa}=61,09 \% \times 2,19 \mathrm{kPa}=1,33 \mathrm{kPa}$

Koefisien Heat Transfer:

$$
\begin{aligned}
& \mathrm{bc}=8,3 \mathrm{v}^{0.6} \text { untuk } 0,2<\mathrm{v}<4.0 \\
& \mathrm{bc}=3,1 \text { untuk } 0,2<\mathrm{v}<4.0
\end{aligned}
$$




$$
\begin{aligned}
& \mathrm{bc}=16,5 \times 3,1=51,15 \mathrm{Wm}^{-2} \mathrm{Kpa}^{-1} \\
& \mathrm{br}=4 \varepsilon \sigma \mathrm{Ar} / \mathrm{AD}\{273,2+(\mathrm{tcl}+\mathrm{tr}) / 2\}^{3} \\
& \text { br }=4,94 \mathrm{Wm}^{-2} \mathrm{Kpa}^{-1}
\end{aligned}
$$

Kombinasi Heat Transfer:

$\mathrm{h}=\mathrm{bc}+\mathrm{br}=51,15 \mathrm{Wm}^{-2} \mathrm{Kpa}^{-1}+4,94 \mathrm{Wm}^{-2} \mathrm{Kpa}^{-1}=56,09 \mathrm{Wm}^{-2} \mathrm{Kpa}^{-1}$

Nilai-nilai hasil perhitungan sebelumnya kemudian disubtitusikan ke dalam persamaan:

$$
\begin{aligned}
\mathrm{C}+\mathrm{R} & =\frac{\text { tsk to }}{\text { Rcl } 1 / f c l x h} \\
\mathrm{C}+\mathrm{R} & =\frac{36,15-35,79}{0.1085+1 / 1,217 \times 7.92} \\
\mathrm{C}+\mathrm{R} & =1,72 \mathrm{~W} \mathrm{~m}^{-2} \\
\text { Esk } & =\frac{P s k, s-P a}{\mathrm{Re}, c l+1 / f c l x b c} \\
\text { Esk } & =\frac{2,23-2,19}{0.015+1 / 1,217 \times 51.15} \\
& =1,28 \mathrm{~W} \mathrm{~m}^{-2} \times \mathrm{W}
\end{aligned}
$$

Untuk $\mathrm{w}=1, \mathrm{Esk}=\mathrm{Emax}=1,28 \mathrm{~W} \mathrm{~m}^{-2}$

$$
\begin{aligned}
\text { Cres }+\mathrm{E} \text { res } & =0,0014 \mathrm{M}(34-\mathrm{ta})+0,0173 \mathrm{M}(5,87-\mathrm{Pa}) \\
& =0,0014 \times 100(34-35,68)+0,0173 \times 100(5,87-2,972) \\
& =4,778 \mathrm{~W} \mathrm{~m}^{-2}
\end{aligned}
$$

Maka persamaan keseimbangan panas menjadi:

$$
\begin{aligned}
& M-W=C+R+E s k+\text { Cres }+E \text { res } \\
& 100-0=1,72+(1,28 \times \text { w })+4,778
\end{aligned}
$$

Jadi kebasahan kulit $(\mathrm{w})=0,98$ akan menyediakan kehilangan panas (heat loss) yang cukup pada kulit melalui penguapan, yaitu tubuh akan berkeringat untuk thermoregulate dan menerima keseimbangan panas. Untuk penguapan maksimum, E max kebasahan adalah 1. Untuk perhitungan di atas memberikan nilai $\mathrm{E} \max =1,28 \mathrm{~W} \mathrm{~m}^{-2}$. Kebasahan yang dibutuhkan untuk keseimbangan dinyatakan dalam persamaan (2)

$$
W_{\text {req }}=\frac{E_{\text {req }}}{E_{\text {max }}}
$$

Dengan demikian: Ereq $\quad=$ Wreq $\times$ Emax $=0.98 \times 1,28=1,25 \mathrm{~W} \mathrm{~m}^{-2}$

Heat stress index (HSI) = Ereq/E Max x 100\%

$$
\begin{aligned}
& =1,25 / 1,28 \times 100 \% \\
& =98 \%
\end{aligned}
$$

Berdasarkan hasil pengolahan dapat diketahui bahwa pengaruh ketinggian terhadap suhu dan pengaruh kelembaban terhadap suhu sangat kuat. Sedangkan berdasarkan kebutuhan energi yang dibutuhkan operator sterilizer maka pekerjaan tersebut termasuk jenis pekerjaan dengan beban sedang sesuai keputusan menteri 
tenaga kerja No.51/KEP-MEN/1999. Sedangkan pengaruh suhu pada operator memiliki risiko yang sangat tinggi yang didasarkan pada nilai HSI sebesar $98 \%$.

\section{KESIMPULAN}

Berdasarkan hasil penelitian yang dilakukan pada operator Sterilizer pada pengolahan pabrik kelapa sawit dapat disimpulkan bahwa risiko operator terpapar panas yang bersumber dari proses perebusan tandan buah sawit sangat tinggi dengan nilai heat stress indeks $98 \%$ atau beban panas dalam keadaan maksimum dan dapat menyebabkan kematian. Sedangkan kategori beban kerja operator sterilizer adalah beban kerja sedang. Dari hasil perhitungan data diperoleh bahwa pengaruh antar ketinggian terhadap suhu, maka diperoleh bahwa semakin tinggi titik pengukuran maka suhu semakin tinggi. Pada suhu yang tinggi diperoleh kelembaban udara yang rendah, pada suhu yang rendah diperoleh kelembaban udara yang tinggi.

\section{SARAN}

Penelitian ini dapat dikembangkan dengan pembahasan yang lebih mendalam tentang pengaturan distribusi panas maupun perancangan alatkerja bagi operator sterilizer yang mampu menyerap panas serta mengendalikan paparan panas. Perancangan isolator mesin terkhusus pada bagian ini serta perancangan tata letak pabrik dan bahan insulasi bangunan yang memperhitungkan keseimbangan panas pada area kerja operator sterilizer.

\section{UCAPAN TERIMA KASIH}

Penulis mengucapkan terima kasih kepada Direktorat Riset dan Pengabdian Masyarakat (DRPM) Kementerian Riset Teknologi dan Pendidikan Tinggi Republik Indonesia yang telah memberi dukungan financial terhadap penelitian ini. Penulis juga mengucapkan terimakasih kepada manajemen PT. $\mathrm{XYZ}$ dan responden atas bantuan dan kerjasamanya sehingga penelitian ini dapat terselesaikan.

\section{DAFTAR PUSTAKA}

ASHRAE., 1985, ASHRAE handbook of fundamentals, Mar Lin Book Company. Huda, L.N. and Pandiangan, K.C., 2012, Kajian Termal Akibat Paparan Panas dan Perbaikan Lingkungan Kerja, Jurnal Teknik Industri, 14(2), pp.129-136.

Salvendy, G., 2012, Handbook of human factors and ergonomics, John Wiley \& Sons.

Stanton, N.A., Hedge, A., Brookhuis, K., Salas, E. and Hendrick, H.W. eds., 2004, Handbook of human factors and ergonomics methods, CRC press.

Walpole, R.E., 1995, Pengantar Statistik Edisi 3 Alih Bahasa: Bambang Sumantri, Gramedia Pustaka Utama, Jakarta. 